MATEC Web of Conferences 48,01005 (2016)

DOI: $10.1051 /$ matecconf $/ 20164801005$

C Owned by the authors, published by EDP Sciences, 2016

\title{
Integrated approach of the dynamic characteristics optimization for spacecraft's technical systems on the exploratory tests
}

\author{
Victor Dmitriev ${ }^{1, a}$ and Yuliya Britova ${ }^{1}$ \\ ${ }^{1}$ National Research Tomsk Polytechnic University, 634050 Tomsk, Russia
}

\begin{abstract}
Integrated approach is the process connecting various project, theoretical and testing procedures. It is provided by the specific series-parallel combination of the mentioned operations. This paper shows that using results of the previous procedures on the further algorithm stages of exploratory tests and product verification is expedient. At that, the necessary correcting of engineering solutions in corresponding procedures is conducted simultaneously. Then, results of each procedure are used in the fixed sequence. It provides maximum attainable optimality of the designed system.
\end{abstract}

\section{Introduction}

This paper presents the dynamic characteristics optimization method of complicated electromechanical system. This method is based on the integrated approach and combines results of analytical design and experimental verification. The suggested method of the integrated approach application in the sophistic technical systems designing such as final controlling element, which based on the torque-controlled reaction wheel motor (RWM), consists of the three stages (Figure 1) [1]:

1. Analytical design;

2. Experimental verification of an engineering sample;

3 . Results analysis and design documents correcting.

All of these stages are visualized by the processes in flow chart. These processes are connected by the functional relations. The flow chart demonstrates the sequence technology of including the necessary engineering solutions correcting in providing processes at the given moment.

\section{Methods. Experimental Procedure}

The analytical design stage is based on the main operational and weight-size parameters, perturbed oscillations, and critical velocity calculations. Also, this stage includes parametric models design, characteristics optimization by the design requirements variation, and calculation of the element's natural frequencies by using special computer-aided systems.

Experimental verification is essential continuation of the reaction wheel motor design. However, this procedure is not only the final part, but closely connects with the other design stages $[2,3]$.

${ }^{\mathrm{a}}$ Corresponding author : dmitriev@tpu.ru 


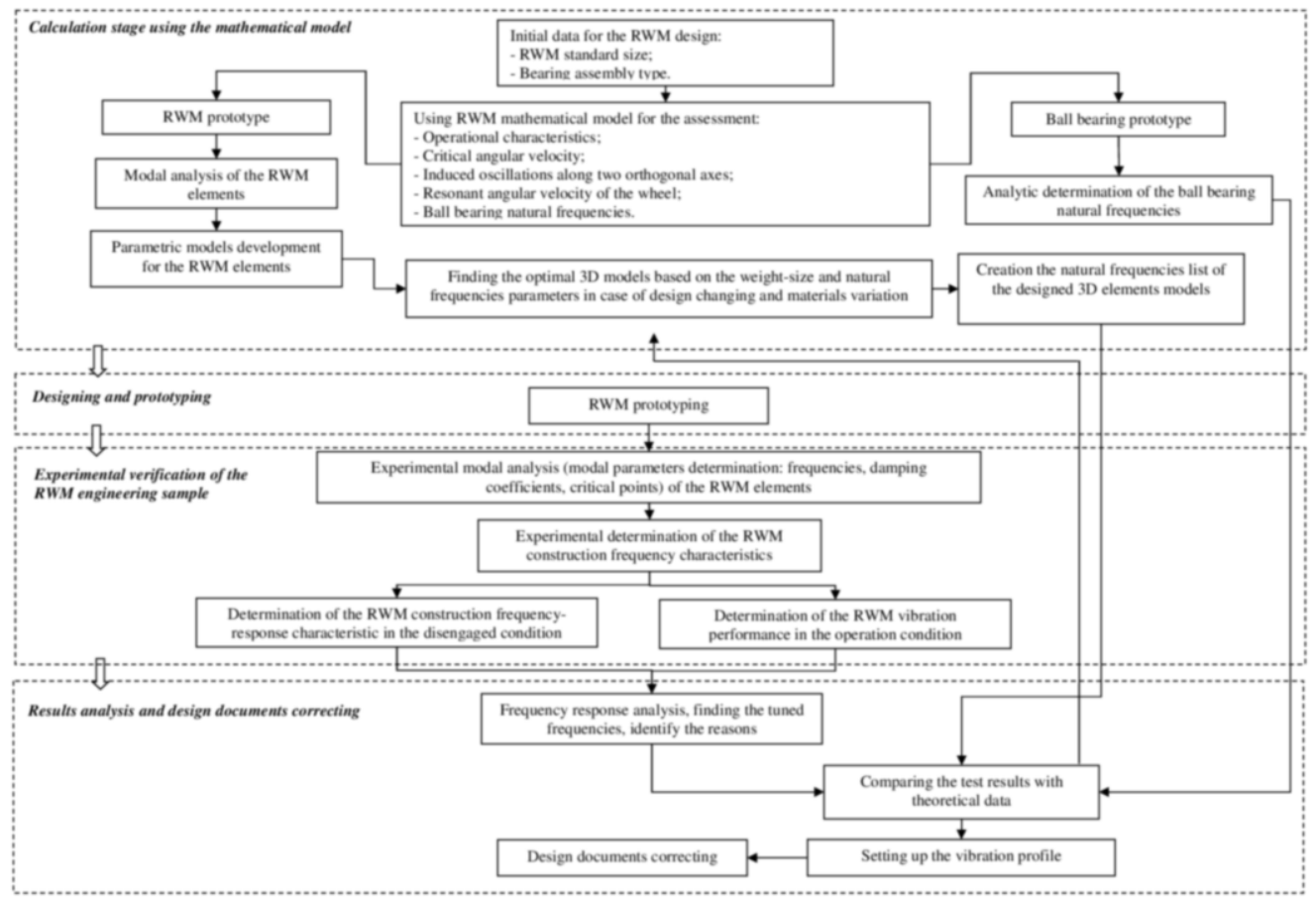

Figure 1. Block scheme of the integrated approach implementation.

Experimental methods for the determination causes of the RWM perturbation actions are based on the highly informative control procedures. At that, control and testing equipment are upgraded with the modern measuring systems based on existing diagnostic and test complex.

In the experimental RWM construction verification the following test types are used:

- Determination of the RWM vibration performance in the operation condition;

- Determination of the RWM tuned frequencies in the disengaged condition under the impact of sine wave vibration generated by the vibration system;

- Experimental modal analysis.

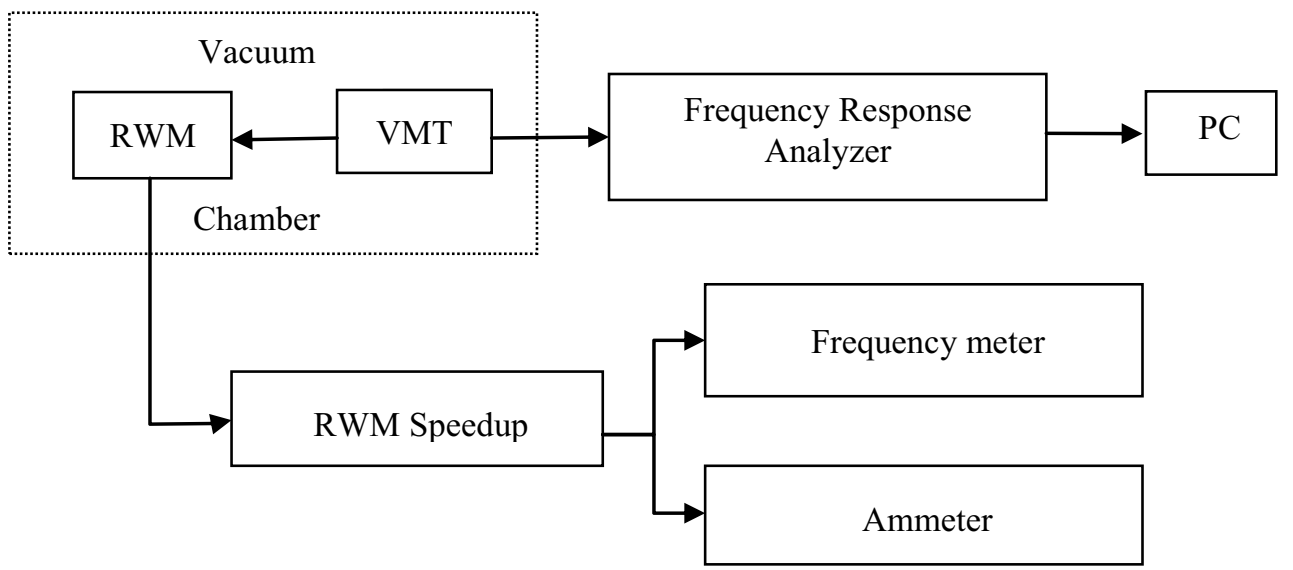

Figure 2. Flow chart of the RWM vibration performance determination: VMT - vibration-measuring transducer; $\mathrm{PC}$ - personal computer. 
These testing approaches base on the modern non-destructive testing methods.

Method for the determination of the RWM construction vibration spectrum in the operation condition based on the vibration level from the construction elements during flywheel speedup and coasting. It can be provided in the angular velocities work range by means of the precision vibrationmeasuring transducers (VMT) [4].

The flow chart of the RWM vibration performance determination is shown in Figure 2.

In general, the RWM vibration performance is represented in Figure 3.

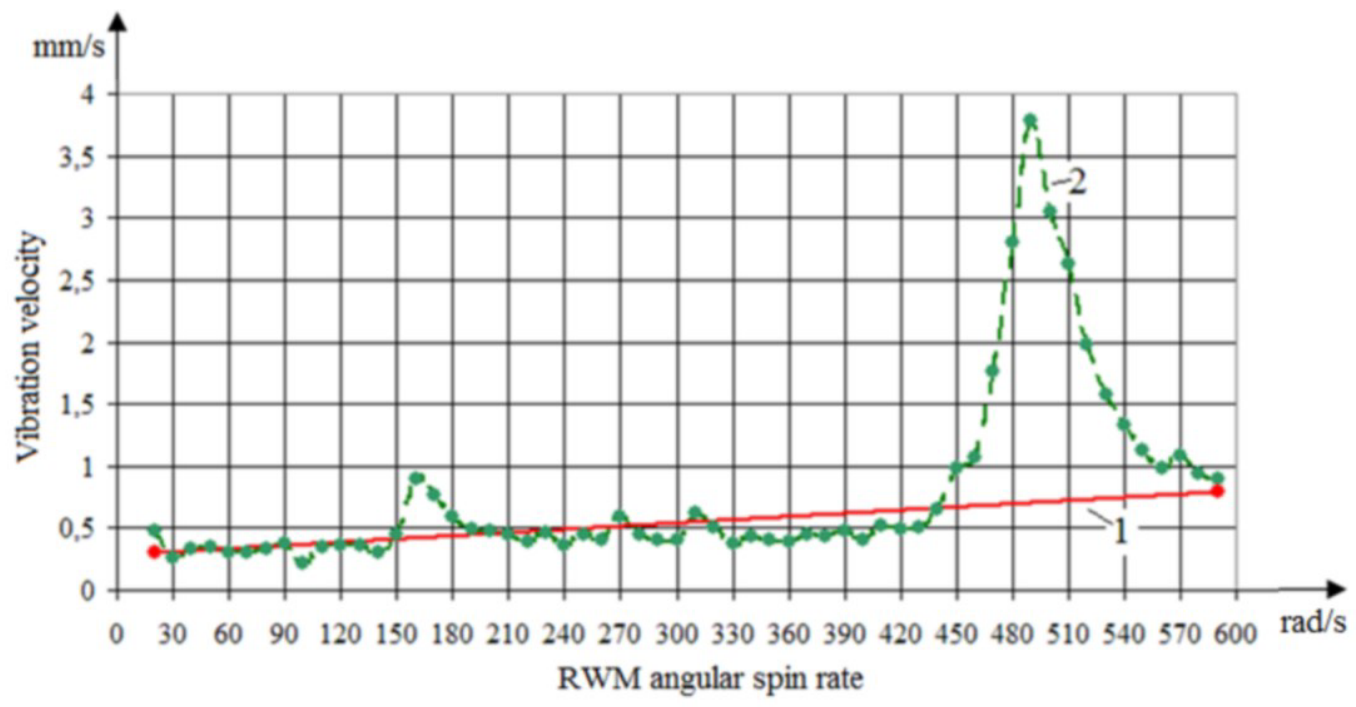

Figure 3. RWM vibration performances: 1 - Ideal; 2 - Investigated RWM.

Analysis and comparison of the obtained data with analytical modeling results and mathematical calculation of the ball bearing natural frequencies (the first stage of the integrated approach) allow identifying the causes of resonance $[5,6]$.

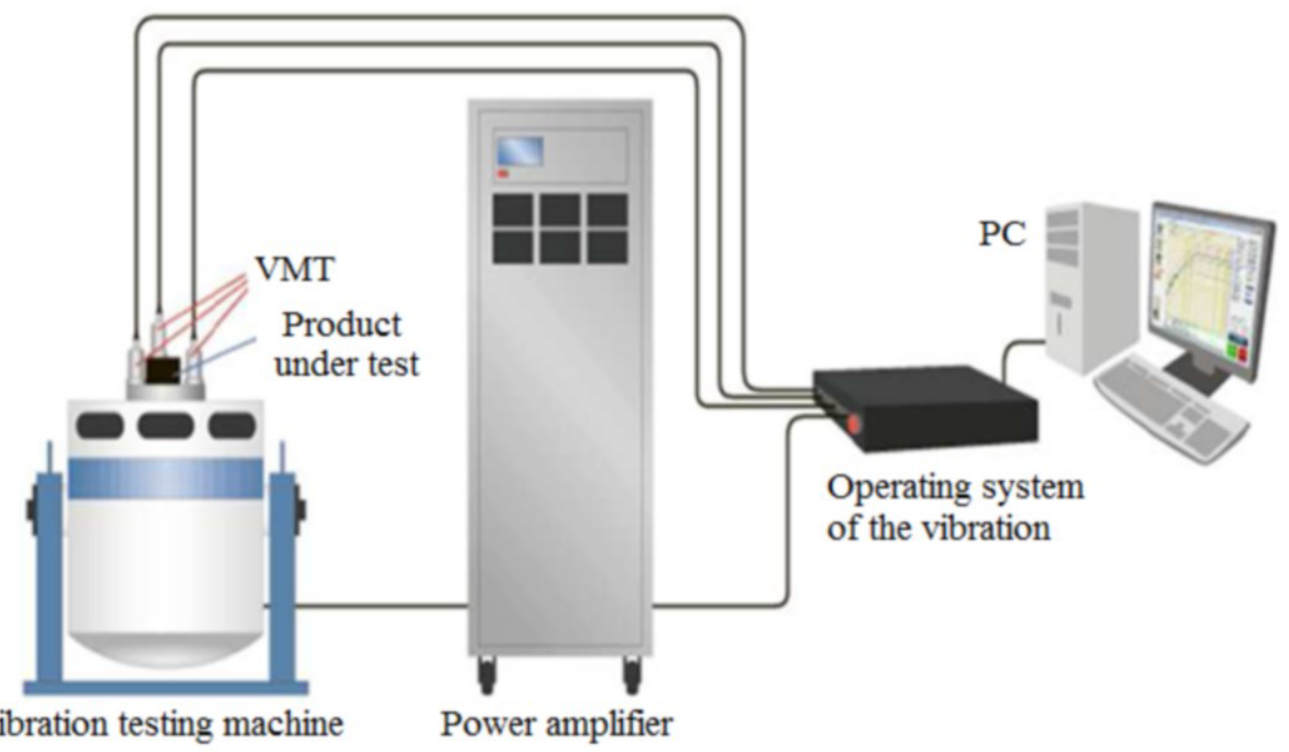

Figure 4. Test setup for the RWM tuned frequencies determination. 


\section{MATEC Web of Conferences}

Identification methodology of the RWM tuned frequencies in the disengaged condition based on the determination frequency response from the RWM construction in three orthogonal axes with normalized impact which generated by vibration system. Test setup for the RWM tuned frequencies determination is illustrated in Figure 4.

As the test result the frequency-response characteristic (FRC) will. It is a graph of acceleration as a function of disturbing frequency.

This frequency-response characteristic can presents the tuned frequencies [7]. Resonant frequency is the frequency where the acceleration amplitude at the measurement point of FRC at two or more times greater than the acceleration amplitude of other frequencies in the spectrum. As an example, Figure 5 shows the RWM`s FRC along X-direction.

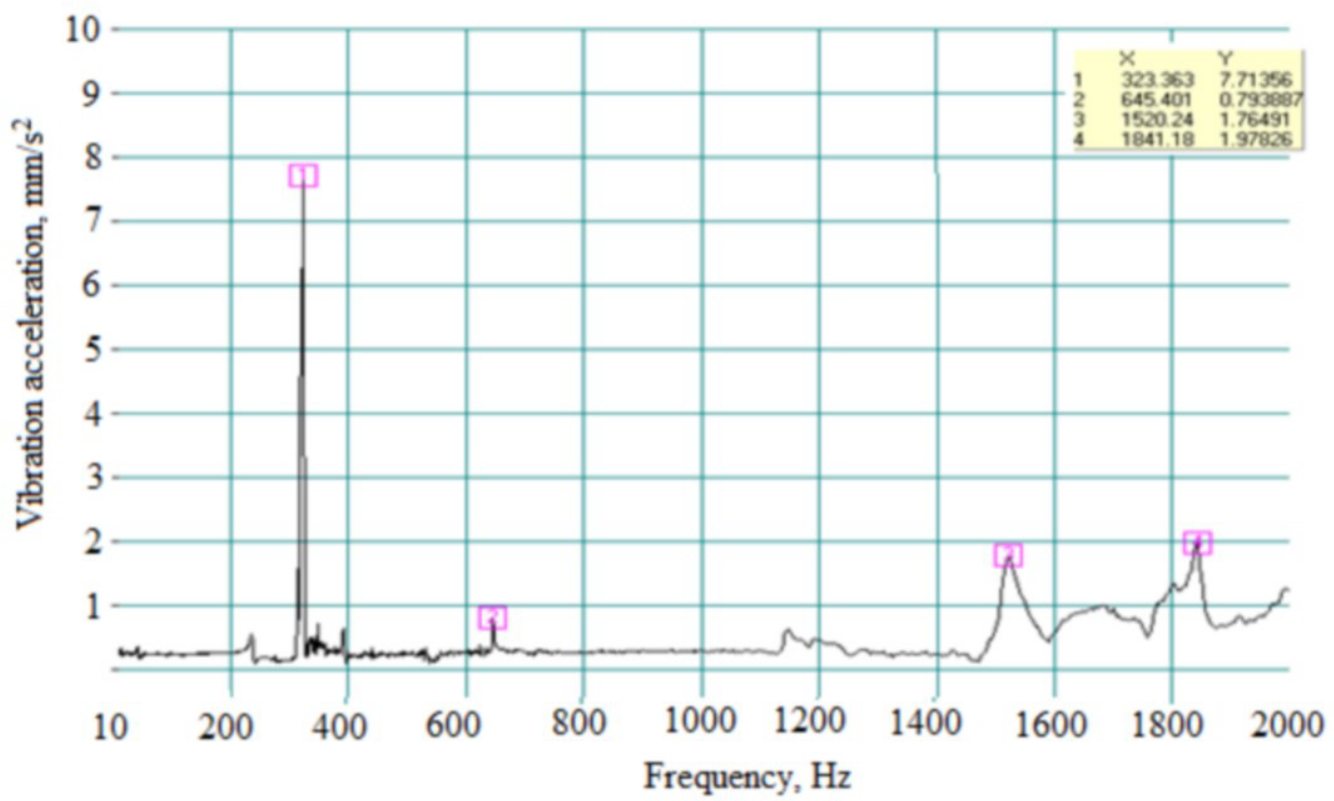

Figure 5. The RWM frequency-response characteristic along X-direction.

The modal parameters determination method (natural frequency, damping coefficient) (the flow chart is represented in Figure 6) of the RWM construction and its elements by the experimental modal analysis based on the calculating frequency response function for a point under the impact by a modal hammer or vibrator.

The experimental modal analysis allows conducting the investigations not only the entire product but also its individual elements [8].

The RWM experimental modal analysis example with using of the impact hammer is shown in Figure 7(a) and with the modal vibrator - Figure 7(b). 


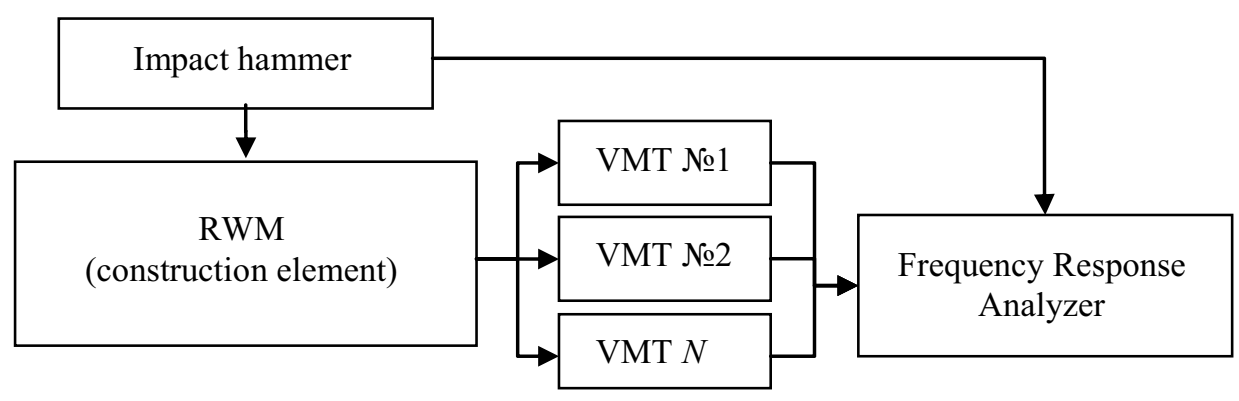

Figure 6. Test Flow Chart for the modal parameters determination.

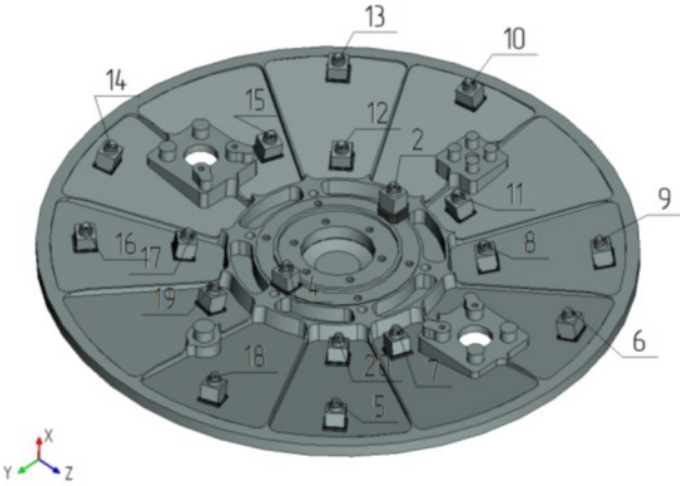

a

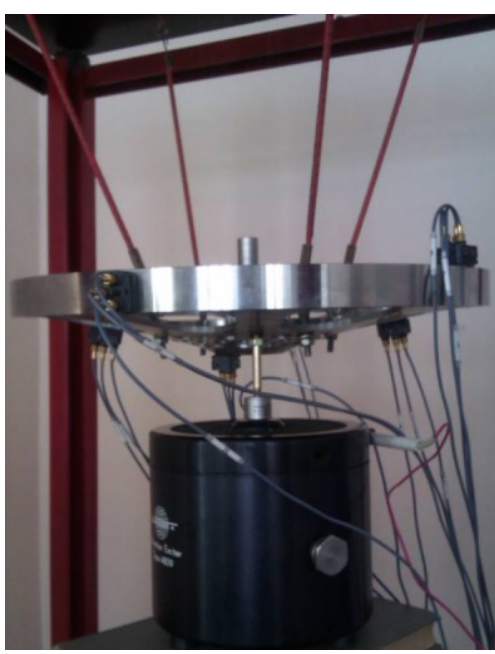

b

Figure 7. Sensors arrangement and force application points on the RWM casing and base.
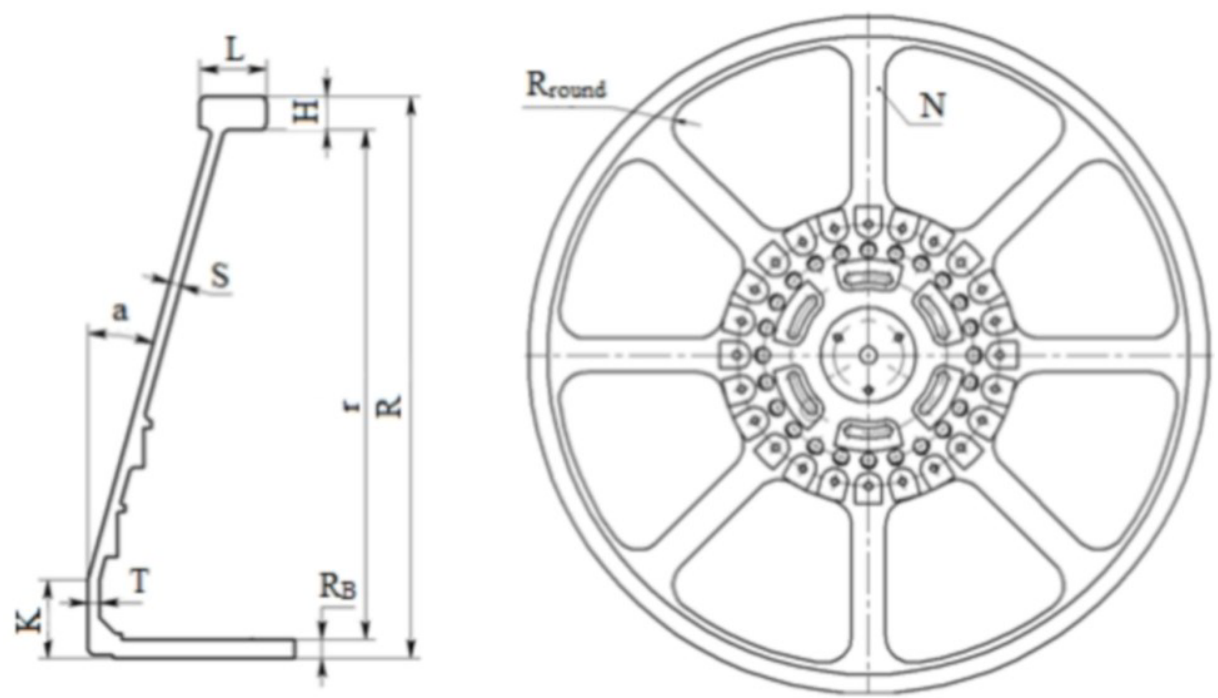

Figure 8. Structural dimensions of the flywheel model.

$\mathrm{R}$ - flywheel outside radius; $\mathrm{r}$ - flywheel inside radius; $\mathrm{L}$ - rim component width; $\mathrm{H}$ - rim component height; a umbilical angle; $\mathrm{S}$ - umbilical thickness; $\mathrm{R}_{\mathrm{B}}$-shaft radius; $\mathrm{T}$ - space thickness for the fixing shaft; $\mathrm{K}$ - width of the space for fixing shaft; $\mathrm{R}_{\text {round }}$ - rounding radius of the umbilical spokes; $\mathrm{N}$ - number of spokes. 


\section{MATEC Web of Conferences}

These frequencies can be compared with the values, which were determined by the modal frequency analysis in a computer-aided design. Frequencies which were identified by a special detail modal analysis can be detected in the RWM`s FRC. In addition, their contribution to the resonance distribution can be assessed. For increasing the "critical" elements, rigidity is necessary to apply to the first stage of the integrated approach and implement the parametric correcting of the selected 3D model construction element.

For instance, the RWM flywheel parametric 3D model is represented in Figure $8[9,10]$.

\section{Conclusion}

Analysis of the RWM vibration performance which was produced during speedup and coasting allows evaluating the impact of the RWM ball bearing natural frequencies on its resonance. Also, it leads to consider the possibility to correct axial load bearing or variation of the radial clearance.

This integrated approach provides developing the RWM construction meets the modern requirements.

The universal character of the developed method expands the number of application opportunities for designing in any complex technical systems.

\section{References}

1. Yu. A. Britova, Thesis work, 12 (2012)

2. S. Mohamady, A. Montazeri, R. Zahari, N. Aswan Abdul, Advances in Acoustics and Vibration 9, $36(2009)$

3. Yu. A. Britova, V. S. Dmitriev, A. A. Vasilcov, I. S. Kostarev, J. Test. Diagn. 11, 221 (2012)

4. W. Fan, P. Qiao, Structural Health Monitoring 10 (1), 83 (2010)

5. X. Guan, G-T. Zheng, Q.-W. Wang, JOA 7, 1870 (2010)

6. M. Wagner, S. Airey, G. Piret, P. Le, European space agency - ESA new reaction wheel characterization test facility (RCF), 142 (2012)

7. M. Pastor, M. Binda, T. Harcarik, Procedia Engineering 48, 543 (2012)

8. D. J. Ewins, Modal Testing - theory, practice and application 5, 60 (2013)

9. Y. T. Leung, JOSV 149, 83 (1991)

10. Yu. A. Britova, A. V. Plotnikov, Materialy nauchno-tehnicheskoj konferencii molodyh specialistov "Informacionnye sputnikovye sistemy» imeni akademika M.F. Reshetneva 1, 213 (2011) 